\title{
A prospective study to evaluate the acceptance, efficacy, side effects and expulsion rates of post-placental intrauterine device
}

\author{
Richa S. Sankhe*, Meenal T. Kamble
}

Department of Obstetrics and Gynecology, Kasturba General Hospital, Mumbai, Maharashtra, India

Received: 05 August 2016

Revised: 18 September 2017

Accepted: 25 September 2017

\section{*Correspondence:}

Dr. Richa S. Sankhe,

E-mail: richasankhe22@gmail.com

Copyright: () the author(s), publisher and licensee Medip Academy. This is an open-access article distributed under the terms of the Creative Commons Attribution Non-Commercial License, which permits unrestricted non-commercial use, distribution, and reproduction in any medium, provided the original work is properly cited.

\begin{abstract}
Background: This study was conducted to know the factors associated with acceptability of immediate post placental IUCD insertion in women and to know the level of safety, efficacy and expulsion of post placental insertion of IUCD. Methods: This study was conducted in Obstetrics and Gynecology Department of Kasturba General Hospital, Mumbai over a period of 1 year. Women admitted and delivered at KGH were informed and counselled regarding intrauterine devices regarding its insertion, efficacy and side effects. $\mathrm{Cu} \mathrm{T} 380 \mathrm{~A}$ was inserted within 15 minutes of delivery of placenta and membranes in women who gave consent and had no contraindications for IUD insertion. All these women were followed for 6 months in the post insertion period.

Results: Total number of women counselled was 400 over the period of six months from August 2015 to January 2016. Out of these only 250 women gave consent for PPIUCD insertion. 50 were lost to follow up. 200 women were followed, out of which 15 women had expulsion, 15 women had excessive bleeding, 20 women complained of pelvic pain, bleeding and abdominal pain together was found in 25 women. 160 out of 200 continued with the method while the rest discontinued.

Conclusions: Based on present study it may be concluded that post placental intrauterine device is an effective method of contraception. Proper counselling and insertion techniques would further improve the acceptability and reduce the expulsion rates.
\end{abstract}

Keywords: Contraception, Post placental intra uterine device, Post placental Insertion

\section{INTRODUCTION}

Contraception methods by definition mean to prevent unwanted pregnancy by temporary or permanently. ${ }^{1}$ Initially contraception was meant for only women. Intrauterine contraceptive device like $\mathrm{Cu}$ T-380A provides contraception up to 10 years. ${ }^{1}$

India is second largest populated country in the world with 120 million according to 2011 census. $^{2}$ It contributes $17.5 \%$ of world's population by adding around 25 million births every year. ${ }^{3}$ A $65 \%$ of women are having unmet need of family planning in the first year of post partum period. ${ }^{3}$ Till 2 years after delivery, a woman will not be ready physically to conceive and delivery. Studies were found that conceiving within two years leads to adverse events like abortion, premature labour, postpartum haemorrhage, low birth weight babies, foetal loss sometimes maternal deaths. Hence advising and practicing contraception with in postpartum period good for women health. ${ }^{4}$

Disseminating family planning methods during postpartum period will be convenient to practice and easy to follow up for complications and adverse events. A total of 127 million women are currently using intra uterine 
contraceptive device. ${ }^{5}$ Lack of information and fear of complications are the common reasons for unmet need. ${ }^{1}$ After female sterilization, IUCD is the most widely used method of contraception. It is a reversible method of contraception in the world. Today around $30 \%$ of couples are using an IUCD, more in the developing countries than developed (United Nation, 2006).

Introduction of JSY and JSSK has increased the number of institutional deliveries. Labour room is attended by large numbers of beneficiaries every day and hence delivery provides a convenient opportunity for the woman to receive IUCD services. This is particularly important for woman who has limited access to medical care. Immediately after delivery, a woman is not ready for next pregnancy. So, it is the time when if she is counselled properly regarding contraception, acceptance level will be very high and if she can be receive contraception facility on the labour table itself, it is very comfortable for women from remote areas in saving time, cost and fear of next pregnancy immediately.

\section{METHODS}

The present study was carried out during the period of one year in the department of Obstetrics and Gynecology, K.G.H, Mumbai. This study is divided in two parts.

- Insertion of IUD (6 months period from Aug. 2015 to Jan. 2016).

- Follow-up (6 months post insertion period up to July 2016).

Women who delivered during the study period and who fulfilled the criteria for post placental IUCD.

\section{Inclusion criteria}

All antenatal patients admitted for delivery to our hospital were counselled for PPIUCD. Written consent was obtained from those who opted for insertion. Those who fulfilled the following criteria were considered for inclusion

- 18-45 years old

- GA 36-40 weeks

- No infections

- $\mathrm{Hb} \geq 8 \mathrm{~g} / \mathrm{dl}$.

\section{Exclusion criteria}

According to medical eligibility criteria for IUCD by WHO,

- Fever during labour and delivery (Temp >38 degree Celsius)

- Having active STD and other genital tract infection or high risk for STD

- Known to have ruptured membranes for $>18 \mathrm{hrs}$ prior to delivery.
- Known uterine abnormalities e. g. Bicornuate/septate uterus, uterine myomas.

- Manual removal of the placenta

- Unresolved postpartum hemorrhage (PPH) requiring use of additional oxytocic agents in addition to AMTSL.

\section{Insertion techniques}

\section{Post-placental insertion}

All necessary instruments (CuT380 A, 2 ring forceps, Sim's speculum, over head lamp, Povidone Iodine, kidney tray and cotton swabs) were arranged on an auxiliary table covered with a sterile drape. Insertion was performed by the consultant using modified Kelly's placental forceps. The patient was placed in a lithotomy position with buttocks at the edge of the table. Aseptic techniques were followed throughout the procedure.

The uterus was palpated to evaluate the height of the fundus and its tone. This is important to assess the size of the uterus to know whether the strings are likely to protrude through the cervix even when $\mathrm{CuT}$ is placed at fundus. After performing the appropriate hand washing, a pair of sterile gloves was worn. The perineum was cleaned with povidone iodine. The perineum, labia, and vaginal walls were inspected for lacerations. Sim's speculum was gently inserted into the vagina to visualize the cervix. The cervix and the vaginal walls were cleaned twice with cotton swabs soaked in povidone iodine solution with speculum in place.

The anterior lip of the cervix was then gently grasped with the same ring forceps used earlier. The IUCD was removed from the insertion sleeve and grasped with the modified Kelley forceps using no-touch technique. Once it is inserted into lower uterine segment. Other hand was removed to abdomen; and placed over the fundus and uterus was pushed gently upward to reduce the angle and curvature between the uterus and vagina. IUCD with forceps was moved upward until it can be felt at the fundus. Then the forceps were opened to release the IUCD and swept to side wall. Uterus was stabilized until forceps removal was complete. The cervical os was then gently inspected for the strings. Sims speculum was removed. She was allowed to take rest for some time.

\section{Intra-caesarean insertion of the IUCD}

Uterine cavity was inspected for presence of malformations following placental delivery, which would limit used of IUCD. The IUCD was removed from the insertion sleeve and placed on the sterile field. Uterus is stabilized by grasping it at fundus. IUCD is hold between middle and index finger. It was inserted into the uterus through uterine incision and released at fundus of uterus. Hand was removed slowly from the uterus. Enough care was taken not to dislodge IUCD as hand is removed. Strings were guided toward the lower uterine segment 
without disturbing IUCDs fundal position. Enough care was taken not to include IUCD strings during uterine closure.

\section{Statistical analysis}

Statistical analysis was performed using SPSS 16.0 software. Unpaired t-test was used to analyze continuous data. Categorical data was compared using Chi-square test. $\mathrm{P}<0.05$ was taken as statistically significant. Relative risk was calculated for abnormal UA PI, UA RI, UA S/D, MCA PI and cerebral-umbilical PI ratio. Multivariate regression was used to analyze effect of multiple variables.

\section{RESULTS}

In the present study, total number of women counselled were 400, among those 250 women accepted post placental insertion of IUD as a method of contraception while 150 denied.

Among these 250 women, $49 \%$ women were educated up to secondary level, $23 \%$ had primary education, $13 \%$ had higher education and rest $15 \%$ had no exposure to formal education. Out of those who accepted the method, most of the women $48 \%$ were second para, $14 \%$ were primipara, $28 \%$ women had $3^{\text {rd }}$ parity and $10 \%$ women were in multipara group.

Among the study group $56 \%$ women had space of $<2 \mathrm{yrs}$ in between last child birth and present delivery, 24\% women had 2-3 yrs spacing while $>4$ yrs of spacing was found only in $7 \%$ of women.

In the present study $62 \%$ of women belonged to low income group while $23 \%$ and $15 \%$ women belong to medium and high income group respectively.

Most common causes of refusal among parturient $(\mathrm{n}=150)$ in the study is given in Table 1.

Table 1: Most common causes of refusal among parturient $(n=150)$.

\begin{tabular}{|l|l|}
\hline Causes of refusal & $\%$ \\
\hline Fear of pain and bleeding & 41 \\
\hline $\begin{array}{l}\text { Interference with sexual intercourse and } \\
\text { partner discomfort }\end{array}$ & 25 \\
\hline Religious superstitions & 20 \\
\hline Fear of cancer & 5 \\
\hline No specific reason & 9 \\
\hline
\end{tabular}

Among the accepted group of women, 50 women were lost to follow-up, only 200 women followed-up to 6 months of post insertion period.

Among the women who came for follow-up ( $n=200), 15$ gave history of expulsion in whom $20 \%$ had expulsion within 7 days, $70 \%$ had within 7-30 days and 10\% after 30 days.

Out of 200 women who came for follow-up 40 women (20\%) insisted for removal of CuT. Reason of removal of IUCD among these women were mentioned in Table 2.

Table 2: Reason of removal of IUCD among women.

\begin{tabular}{|ll|}
\hline Reason of removal of IUCD & $\%$ \\
\hline Bleeding and pelvic pain & 15 \\
\hline Familial pressure & 5 \\
\hline Missing thread of $\mathrm{Cu}-\mathrm{T}$ & 5 \\
\hline
\end{tabular}

Some women with post placental IUCD insertion came with the following complications:

- $\quad$ Excessive bleeding only $(7.5 \%)$

- Pelvic pain only (10\%)

- $\quad$ Bleeding and pelvic pain $(12.5 \%)$

Amongst women without any complaints (125 women out of 300), 6 women (3\%) insisted for removal of IUD under family pressure.

Overall 40 women $(20 \%)$ did not continue IUCD. 160 women $(80 \%)$ continued IUCD at 6 months follow-up.

\section{DISCUSSION}

In this study majority of the women $(75 \%)$ had at least primary level of education. Acceptance of post placental IUCD was higher among women with primary and secondary education confirming the importance of education in deciding future pregnancy. Women who completed secondary education were about twice as likely to use modern contraceptive methods as compared to women who did complete primary education. ${ }^{6}$

This study shows role of education in acceptance of contraceptive methods as studied by Safwat et al. ${ }^{7}$ In Egypt a, significant number of women denied PPIUCD because of partner's unwillingness. This reveals the importance of partner and family in involvement during counselling and decision making. Healthy timing and spacing of pregnancies have a positive effect on maternal health and newborn outcomes. ${ }^{8}$ Acceptance of intrauterine contraceptive device was the most common among multiparous women (48\%). This finding is in accordance to that of the study by Grimes et al where they found higher acceptance in multiparous clients $(65.1 \%){ }^{9}$

The duration since last child birth was significantly associated with acceptance of PPIUCD. About $56 \%$ of the PPIUCD acceptors had their last child birth less than 2 yrs. Women who came for first delivery with short pregnancy interval felt the need for a long acting and reliable method of contraception. In a report released by WHO in 2006, better family planning and birth spacing 
services resulted in better maternal and neonatal outcome. When promoted in countries with high birth rates, $32 \%$ of all maternal deaths and over one million deaths of children under 5 yrs could be prevented. Healthy timing and spacing of pregnancies have a positive effect on maternal health and new born outcomes. ${ }^{10}$ This finding in the study indicates towards a positive maternal health in future.

Expulsion rate of IUCD in our study was $10 \%$, expulsion of PPIUCD usually occur in the first few months. In present study expulsion rate of PPIUCD within 7 days was $2 \%$ and within 4 weeks was $7 \%$. This was similar to multi country study done in Belgium, Chile and Philippines which showed the rate of expulsion at one month ranging from 4.6 to $16 \% .{ }^{11}$ In the present study, there were no cases of PID. A study conducted in 13 countries studies infection (PID) due to IUD. They have reported similar rate of infection with immediate insertion and interval insertion. Another trial did not find any instance of infection due to post-partum IUCD.

The acceptance of PPIUCD was high in present study and it is comparable to other studies done globally. Awareness of PPIUCD among these women was very poor despite high acceptance. Majority of the women had never heard about PPIUCD before admission to labour room. Parturient who had a short duration from their last child birth $(<2 \mathrm{yrs})$ and multigravidas had greater acceptance of PPIUCD.

Acceptance was high among women who at least had primary education. The PPIUCD was demonstrably safe, having no reported incidence of perforation with low rates of expulsion, pelvic infection, and few lost strings. We can conclude that inserting CuT 380A within $10 \mathrm{~min}$ after placental delivery is safe, effective and has a high retention rate. The expulsion rate was not high and further can be reduced with practice. With the high level of acceptance, despite low levels of awareness, the government needs to develop strategies to increase public awareness of the PPIUCD through different media sources. It is also important to give training on PPIUCD in order to increase knowledge and skills among health care providers. This will also further promote PPIUCD use and aid in reduction of the expulsion rates. In a nation which moves with discounts, subsidies and incentives, cash incentives to the acceptor, motivator and of course, provider would bring about a substantial progress in the PPIUCD use in developing countries like India.

Funding: No funding sources Conflict of interest: None declared

Ethical approval: The study was approved by the Institutional Ethics Committee

\section{REFERENCES}

1. Park K. Park's text book of social and preventive medicine. $23^{\text {rd }}$ ed. Jabalpur: Banarsidas Bhanot; 2015.

2. India at Glance - Population census 2011. Census organization of India, 2011. Available at: http://censusindia.gov.in/2011-prov-

results/indiaatglance.html. Accessed on $21^{\text {st }}$ July 2015.

3. Post-partum. IUCD reference manual. New Delhi: Family Planning Division, Ministry of Health and Family Welfare, Government of India; 2010.

4. Kanhere A, Pateriya P, Jain M. Acceptability and Feasibility of Immediate post-partum IUCD insertion in a tertiary care centre in Central India. Int J Reprod Contracept Obstet Gynecol. 2015;4(1):1.

5. Nelson A. Intrauterine contraceptives. vol. 6. Philadelphia: Lippincott Williams and Wilkins; 2004. Gynaecology and Obstetrics. In: 2.

6. Thomas D. Maluccio J. Fertility, contraceptive choice, and public policy in Zimbabwe. World Bank Econ Rev. 1996;10(1):189-222.

7. Mohamed SA, Kamel MA, Shaaban OM, Salem HT. Acceptability for the use of postpartum intrauterine contraceptive devices: assiut experience. Med Princ Pract. 2003;12:170-5.

8. Maternal and Child Health Integrated Program and PPFP activities, WHO Report. Available at http://www.k4health.org/sites/default/files/PPFPMee ting Report_formatted.pdf.

9. Grimes D, Schulz K, Van Vliet H, Stanwood N. Immediate post-partum insertion of intrauterine devices: a Cochrane review. Hum Reprod. 2001;17(3):549-54.

10. Maternal and Child Health Integrated Program and PPFP activities, WHO Report. Available at http://k4health.org/sites/default/files/PPFPMeetingR eport_formatted.pdf

11. Blanchard H. Mac Kaig C. ACCESS-FP Program. 2006. Postpartum contraception. Available at http://www.k4health.org/sites/default/files/postpartu mabortion_english.pdf.

Cite this article as: Sankhe RS, Kamble MT. A prospective study to evaluate the acceptance, efficacy, side effects and expulsion rates of postplacental intrauterine device. Int J Reprod Contracept Obstet Gynecol 2017;6:4821-4. 